\title{
HIV screening and retention in care in people who use drugs in Madrid, Spain: a prospective study
}

Pablo Ryan ${ }^{1,2,3 \dagger}$, Jorge Valencia ${ }^{1,4+}$, Guillermo Cuevas', Jesús Troya', Juan Torres-Macho', María José Muñoz-Gómez ${ }^{5}$, Nuria Muñoz-Rivas ${ }^{1}$, Isabel Canorea ${ }^{5}$, Sonia Vázquez-Morón ${ }^{5 \dagger}$ and Salvador Resino ${ }^{{ }^{*}+}$ (1)

\begin{abstract}
Background: The burden of human immunodeficiency virus (HIV) infection in people who use drugs (PWUD) is significant. We aimed to screen HIV infection among PWUD and describe their retention in HIV care. Besides, we also screen for hepatitis C virus (HCV) infection among HIV-seropositive PWUD and describe their linkage to care.

Methods: We conducted a prospective study in 529 PWUD who visited the "Cañada Real Galiana" (Madrid, Spain). The study period was from June 1, 2017, to May 31, 2018. HIV diagnosis was performed with a rapid antibody screening test at the point-of-care (POC) and HCV diagnosis with immunoassay and PCR tests on dried blood spot (DBS) in a central laboratory. Positive PWUD were referred to the hospital. We used the Chi-square or Fisher's exact tests, as appropriate, to compare rates between groups.

Results: Thirty-five (6.6\%) participants were positive HIV antibodies, but 34 reported previous HIV diagnoses, and 27 (76\%) had prior antiretroviral therapy. Among patients with a positive HIV antibody test, we also found a higher prevalence of homeless $(P<0.001)$ and injection drug use (PWID) $(P<0.001)$, and more decades of drug use $(P=0.002)$. All participants received HIV test results at the POC. Of the 35 HIV positives, 28 (80\%) were retained in HIV medical care at the end of the HIV screening study (2018), and only 22 (62.9\%) at the end of 2020. Moreover, 12/35 (34.3\%) were positive for the HCV RNA test. Of the latter, 10/12 (83.3\%) were contacted to deliver the HCV results test (delivery time of 19 days), 5/12 (41.7\%) had an appointment and were attended at the hospital and started HCV therapy, and only 4/12 (33.3\%) cleared HCV.

Conclusions: We found almost no new HIV-infected PWUD, but their cascade of HIV care was low and remains a challenge in this population at risk. The high frequency of active hepatitis C in HIV-infected PWUD reflects the need for HCV screening and reinforcing the link to care.
\end{abstract}

Keywords: HIV, Point-of-care, Screening, People who use drugs, Retention in care, Hepatitis C, Dried blood spot, Antiviral treatment

\footnotetext{
*Correspondence: sresino@isciii.es

†Pablo Ryan, Jorge Valencia, Sonia Vázquez-Morón, and Salvador Resino have contributed equally to this work.

${ }^{5}$ Unidad de Infección Viral e Inmunidad, Centro Nacional de

Microbiología, Instituto de Salud Carlos III, Carretera MajadahondaPozuelo, Km 2.2, 28220 Majadahonda, Madrid, Spain

Full list of author information is available at the end of the article
}

\section{Background}

Human immunodeficiency virus (HIV) infection in people who use drugs (PWUD), such as cocaine and heroin, is a significant global issue, particularly among people who have injected drugs (PWID) [1]. The global HIV prevalence in PWID is $17.8 \%$, and around $50 \%$ are original author(s) and the source, provide a link to the Creative Commons licence, and indicate if changes were made. The images or other third party material in this article are included in the article's Creative Commons licence, unless indicated otherwise in a credit line to the material. If material is not included in the article's Creative Commons licence and your intended use is not permitted by statutory regulation or exceeds the permitted use, you will need to obtain permission directly from the copyright holder. To view a copy of this licence, visit http://creativecommons.org/licenses/by/4.0/. The Creative Commons Public Domain Dedication waiver (http://creativeco mmons.org/publicdomain/zero/1.0/) applies to the data made available in this article, unless otherwise stated in a credit line to the data. 
hepatitis $\mathrm{C}$ virus (HCV) antibody-positive [2]. Despite this, the incidence of new HIV and HCV diagnoses among PWID has decreased sharply since 2010 due to the implementation of harm reduction services and treatment as prevention strategies [3-6]. However, the level of coverage of these strategies is different and varies among regions and remains low globally [7].

PWUD are exposed to multiple adverse environments that can increase the risk of HIV and HCV acquisition $[8,9]$. The most determining factors in increasing the risk of HIV and $\mathrm{HCV}$ acquisition are intravenous drug use, increased frequency of injection, syringe sharing, homelessness, incarceration, and exposure to physical and sexual violence, among others [8-12]. Both HIV and HCV infections are usually diagnosed at hospitals using standardized tests, but this causes very high tracking losses among PWUD. Strategies to scale up HIV and HCV testing, such as rapid tests at the point of care (POC) and the use of mobile medical units, increase the probability of diagnosis among PWUD [13, 14]. Another alternative is the use of dried blood samples (DBS) and to carry out the diagnosis in reference centers. However, this strategy has limitations, such as the diagnosis is delayed and hinder the link with medical care $[15,16]$.

The HIV continuum of care may be used as a public health tool to measure the effectiveness of health systems and monitor progress towards the goals set to end the HIV epidemic, consisting of several steps required to achieve HIV suppression $[17,18]$. However, different definitions of the HIV continuum of care are used according to countries, and there are disparities between population subgroups [19]. Moreover, linkage and retention in care after HIV diagnosis present unique challenges for PWUD infected with HIV [13, 20]. The most limiting factors related to low HIV retention in care are the mistrust between providers and PWUD, intravenous drug use, binge drinking, younger age, ethnic minorities, HCV coinfection, psychiatric illness, lack of insurance, male sex, and low education level [13, 21]. Besides, both HIV and HCV therapies can only be prescribed at specialized health centers, where PWUD do not usually go, making the treatment still inadequate $[13,14]$. Therefore, holistic services are essential to HIV retention in care for PWUD, including health insurance, counseling, adherence support, mental health, substance abuse treatment, and housing assistance [17]. Data related to people retained in HIV care in PWUD attended in harm reduction services remain scarce. We aimed to screen HIV infection among PWUD and describe their retention in HIV care. Besides, we also screen for HCV infection among HIVseropositive PWUD and describe their linkage to care.

\section{Methods}

\section{Study design}

We conducted a prospective study in 529 PWUD in the last year and who visited the "Cañada Real Galiana" (Madrid, Spain), a shantytown where much of the illicit drugs of the region are sold and consumed. Around 4000-6000 people a day get to this place to obtain drugs, and a rapid HIV test was offered to everyone by order of appearance (consecutive sampling). They were invited to a screening of blood-borne infections, and all HIV tests were performed before the interview. The study period was from June 1, 2017, to May 31, 2018, when the time limit established in the research project was reached. The inclusion criteria were: (1) age $\geq 18$ years; (2) PWUD; (3) ability to sign informed consent; (4) provide contact information for its subsequent location in case of having a positive result. This cohort has previously described in a study about HCV screening [22].

In the HIV screening phase (baseline), a mobile unit consisting of a van adapted for the project and a satellite car was used. In this mobile unit, a trained nurse and a navigator/educator performed HIV screening using the OraQuick ADVANCE Rapid HIV-1/2 Antibody Test (OraSure Technologies, Bethlehem, PA, USA). The sensitivity and specificity of this HIV antibody test is $98 \%$ and $100 \%$, respectively [23]. The test results were returned in $20 \mathrm{~min}$; time used to collect epidemiological data, and recommend prevention and harm reduction. Moreover, we collected fingerstick DBS using Whatman cards and sent them to the Instituto de Salud Carlos III (ISCIII) to determine HCV antibodies and HCV RNA. In this case, the $\mathrm{HCV}$ screening results were given to the participant 1 to 2 weeks later.

In the linkage and retention in care phase (followup), participants with a rapid HIV serological test were offered to be referred to the hospital the same day, both to participants with a new HIV diagnosis and those known diagnoses. In Spain, HIV treatment is only prescribed by a physician at hospitals. HIV-infected patients were transported to the hospital by car, and the navigator accompanied the patient during the process of initiation or re-initiation of antiretroviral therapy (ART). Most of the patients were transported to the Fast-Track Clinic at "Infanta Leonor" Hospital, due to the geographic proximity, where patients were examined and treated against HIV infection. Retention in care was measured at two points in time (2018 and 2020) by asking patients whether they had an appointment at the HIV clinic and received ART in the previous year. This information was further confirmed by consulting the medical records.

Moreover, HIV-infected patients with active hepatitis C were also contacted and referred to the hospital, but several days later, where were examined and treated against 
$\mathrm{HCV}$ infection. In this case, the navigator also accompanied the patient to the hospital to initiate HCV treatment and to confirm the cure of hepatitis $C$, that is, to achieve a sustained virological response (SVR) defined as undetectable serum HCV RNA 12 weeks after completing antiviral treatment with direct antiviral agents. When a patient refused to be referred to the hospital that day, he was subsequently contacted to try referral another day.

\section{Data management}

Epidemiological data (sex, age, nationality, income, and homeless status), substance abuse [time of drug use, type of drug used, the current route of drug administration, daily alcohol intake, benzodiazepine, and injecting drug users (IDUs)], healthcare (regular medical care, health insurance, previous anti-HIV testing, opioid substitution therapy, and psychiatric treatment), and sexual risk behavior (stable partner, men who have sex with men and commercial sex work) in the past 12 months were collected by researchers at the POC by an online form on a mobile device (the participant did not self-complete any form/information) using the Research Electronic Data Capture (REDCap, Vanderbilt University, Nashville, TN, USA) [24], hosted at the Asociación Ideas for Health. Clinical data related to the diagnosis and treatment of HIV infection were collected from hospital medical records.

The homeless lived on the street or in a homeless shelter. The alcohol intake ( $>50 \mathrm{~g} /$ day) was self-reported. PWUD were those who had ever used drugs in the last year. PWID were those who ever used intravenous drugs in the previous year.

\section{Laboratory assays}

DBS samples were obtained by fingerstick using Whatman 903 cards, dried for four hours at room temperature $\left(\sim 25{ }^{\circ} \mathrm{C}\right)$, and subsequently stored at $4{ }^{\circ} \mathrm{C}$ in individual plastic bags with a desiccant and zipped closed. Then, within 15 days of collection, samples were sent refrigerated $\left(\sim 4{ }^{\circ} \mathrm{C}\right)$ to the ISCIII and stored at $-80{ }^{\circ} \mathrm{C}$ until processing. We processed DBS samples according to the described protocol [25]. Briefly, two discs from the Whatman 903 cards were added to a solution with $0.05 \%$ Tween in PBS at $25{ }^{\circ} \mathrm{C}$. After, samples were centrifuged at $1200 \times g$ for $30 \mathrm{~min}$ and incubated overnight at $4{ }^{\circ} \mathrm{C}$. On the morrow, DBS eluates were stored at $-80^{\circ} \mathrm{C}$ until analysis.

DBS eluates were tested for HIV and HCV. We evaluated anti-HIV antibodies (Murex HIV Ag/Ab Combination Kit, DiaSorin, Saluggia, Italy), anti-HCV antibodies (Murex anti-HCV kit, v. 4.0, DiaSorin, Saluggia, Italy) in the eluates using an ETI-Max 3000 instrument (DiaSorin, Saluggia, Italy). According to a previously described protocol [25], the diagnosis of active hepatitis $C$ was performed only in people with positive $\mathrm{HCV}$ antibodies. HCV RNA was extracted using the mini-kit DSP Virus/ Pathogen (Qiagen, Hilden, Germany) and was detected using a qualitative SYBR Green RT-PCR assay, with a limit of detection of $960 \mathrm{IU} / \mathrm{ml}$.

\section{Outcome variables}

We analyzed a series of outcome variables related to (1) HIV: HIV infection (positive OraQuick rapid test) and HIV retention in care (having an appointment at the hospital and receiving HIV therapy). (2) Hepatitis C: HCV infection (positive anti-HCV test and positive HCV-RNA test) and $\mathrm{HCV}$ linkage to care [delivering of $\mathrm{HCV}$ test results; having an appointment at the hospital; being seen by a physician once at the hospital; starting HCV therapy, and achieving sustained virological response (SVR)].

\section{Statistical analysis}

Statistical analysis of the population description was performed using the Mann-Whitney tests for continuous variables and the Chi-square or Fisher's exact tests for categorical variables, as appropriate. Besides, the rates of patients infected with HIV and HCV and patient retention in HIV care were compared between groups using Chi-square or Fisher's exact tests. We also analyze the association between the significant characteristics of the patients (see Table 1) and a positive result in the HIV test by multivariate logistic regression.

All statistical analyses were performed using IBM SPSS v25 (IBM Corp, Armonk, NY, USA). Figures were created using GraphPad Prism v8.0 (GraphPad Software, Inc., San Diego, CA, USA). All $P$-values were two-tailed. Statistical significance was considered with $P<0.05$.

\section{Results}

\section{Characteristics of the study population}

Overall, the population had an age of 42 years, 79\% were male, $20 \%$ were homeless, and $21 \%$ were migrants (Table 1). Regarding drug use, $46.8 \%$ had used drugs for more than 20 years, heroin and cocaine were the most used drugs, and around 50\% had previously injected drugs. Regarding healthcare, $88 \%$ of participants had usual care in a primary health center, $11 \%$ were never tested for HIV infection, 35\% had not been tested for HIV infection in the last year, and $28 \%$ had taken opioid substitution therapy. Concerning sexual risk behaviors, $46 \%$ of participants had a stable partner, and $19 \%$ had sexual behavior at risk of HIV infection.

\section{HIV screening and linkage to care}

We found 35/529 participants with positive HIV antibodies by rapid HIV test $[6.6 \%, 95 \%$ confidence interval $(C I)$ 
Table 1 Baseline epidemiological characteristics of the population screened

\begin{tabular}{|c|c|c|c|c|}
\hline Characteristics & All & HIV (-) & $\operatorname{HIV}(+)$ & $P$-value \\
\hline$n$ & 529 & 494 & 35 & \\
\hline Age (years) & $42(35 ; 48)$ & $42(34 ; 48)$ & $48(41 ; 50)$ & 0.003 \\
\hline$<30$ & $47(8.8 \%)$ & 47 (9.5\%) & $0(0.0 \%)$ & n.s \\
\hline $30-40$ & 161 (30.4\%) & $154(31.2 \%)$ & $7(20.0 \%)$ & n.s \\
\hline $40-50$ & $216(40.8 \%)$ & $198(40.1 \%)$ & $18(51.4 \%)$ & n.s \\
\hline$\geq 50$ & $105(19.8 \%)$ & $95(19.2 \%)$ & $10(28.6 \%)$ & n.s \\
\hline Male & $420(79.4 \%)$ & $392(79.3 \%)$ & $28(80.0 \%)$ & n.s \\
\hline \multicolumn{5}{|l|}{ Origin } \\
\hline Spain & 419 (79.2\%) & 392 (79.3\%) & $27(77.1 \%)$ & n.s \\
\hline Eastern Europe & 55 (10.4\%) & 49 (9.9\%) & $6(17.1 \%)$ & n.s \\
\hline Western Europe & $17(3.2 \%)$ & $16(3.2 \%)$ & $1(2.8 \%)$ & n.s \\
\hline North Africa & $23(4.3 \%)$ & $22(4.4 \%)$ & $1(2.8 \%)$ & n.s \\
\hline America & $7(1.3 \%)$ & $7(1.4 \%)$ & $0(0.0 \%)$ & n.s \\
\hline Other & $8(1.5 \%)$ & $8(1.6 \%)$ & $0(0.0 \%)$ & n.s \\
\hline Homeless & 105 (19.9\%) & $90(18.3 \%)$ & $15(42.8 \%)$ & $<0.001$ \\
\hline \multicolumn{5}{|l|}{ Drugs use } \\
\hline \multicolumn{5}{|l|}{ Decades of drug use $(n=489)$} \\
\hline$<1$ year & $6(1.2 \%)$ & $6(1.3 \%)$ & $0(0.0 \%)$ & n.s \\
\hline $1-9$ years & $83(17.0 \%)$ & $82(18.0 \%)$ & $1(2.9 \%)$ & 0.024 \\
\hline 10-19 years & $171(35.0 \%)$ & $165(36.3 \%)$ & $6(17.6 \%)$ & 0.028 \\
\hline 20-29 years & $134(27.4 \%)$ & $120(26.4 \%)$ & $14(41.2 \%)$ & n.s \\
\hline$\geq 30$ years & $95(19.4 \%)$ & $82(18.0 \%)$ & $13(38.2 \%)$ & 0.004 \\
\hline \multicolumn{5}{|l|}{ Type of drug used } \\
\hline Heroin & $412(78.0 \%)$ & $383(77.5 \%)$ & $29(82.9 \%)$ & n.s \\
\hline Cocaine & $476(90.0 \%)$ & $443(90.0 \%)$ & $33(94.3 \%)$ & n.s \\
\hline Marihuana & $71(13.4 \%)$ & 69 (14.0\%) & $2(5.7 \%)$ & n.s \\
\hline Alcohol (> 50 g/day) & $50(9.4 \%)$ & $49(9.9 \%)$ & $1(2.8 \%)$ & n.s \\
\hline \multicolumn{5}{|l|}{ Go for drugs daily } \\
\hline \multicolumn{5}{|l|}{ The current route of drug administration } \\
\hline Injected & $177(33.4 \%)$ & $149(30.2 \%)$ & $28(80.0 \%)$ & $<0.001$ \\
\hline Smoked & $432(81.6 \%)$ & $404(81.8 \%)$ & $28(80.0 \%)$ & n.s \\
\hline Snorted & $135(25.5 \%)$ & $130(26.3 \%)$ & $5(14.3 \%)$ & n.s \\
\hline Benzodiazepines prescribed & $39(7.4 \%)$ & $35(7.1 \%)$ & $4(11.4 \%)$ & n.s \\
\hline Had injected drugs (IDUs) & $254(49.7 \%)$ & $223(46.8 \%)$ & $31(88.6 \%)$ & $<0.001$ \\
\hline Shared syringes in the previous year & $21(8.5 \%)$ & $17(7.9 \%)$ & $4(13.3 \%)$ & n.s \\
\hline Shared paraphernalia in the previous year & $90(40.4 \%)$ & $89(40.6 \%)$ & $1(25.0 \%)$ & n.s \\
\hline IDUs active in the previous year & $127(26.6 \%)$ & $118(26.6 \%)$ & $9(26.5 \%)$ & n.s \\
\hline \multicolumn{5}{|l|}{ Healthcare } \\
\hline No health insurance & $74(15.4 \%)$ & $67(14.9 \%)$ & $7(21.9 \%)$ & n.s \\
\hline Primary care assistance & $138(26.1 \%)$ & $134(24.1 \%)$ & $4(11.4 \%)$ & 0.041 \\
\hline Never tested for HIV & $57(11.6 \%)$ & $57(11.6 \%)$ & $0(0.0 \%)$ & n.s \\
\hline Last HIV test > 1 year & $124(34.8 \%)$ & $122(34.7 \%)$ & $2(50.0 \%)$ & n.s \\
\hline Opioid substitution therapy & $142(27.7 \%)$ & $123(25.8 \%)$ & $19(54.3 \%)$ & $<0.001$ \\
\hline On psychiatric treatment & $148(28.9 \%)$ & $134(28.1 \%)$ & $14(41.2 \%)$ & n.s \\
\hline \multicolumn{5}{|l|}{ HCV-related sexual risk behavior } \\
\hline Stable partner & $204(46.3 \%)$ & $188(45.6 \%)$ & $16(55.2 \%)$ & n.s \\
\hline Sexual risk behavior in last year & $57(19.1 \%)$ & $56(20.3 \%)$ & $1(4.5 \%)$ & n.s \\
\hline Men who have sex with men & $9(2.7 \%)$ & $7(2.3 \%)$ & $2(8.3 \%)$ & n.s \\
\hline Commercial sex work (only women) & $34(9.6 \%)$ & $31(9.4 \%)$ & $3(12.5 \%)$ & n.s \\
\hline
\end{tabular}

Statistics: Values are expressed as number (percentage) and median (interquartile range)

$H C V$ hepatitis $C$ virus; IDU injection drug user; $P$-value level of significance; $n$.s. not significant 
Table 2 Sociodemographic and epidemiological characteristics associated with HIV infection among people who use drugs

\begin{tabular}{|c|c|c|c|c|}
\hline \multirow[t]{2}{*}{ Variables } & \multicolumn{2}{|l|}{ Univariate } & \multicolumn{2}{|l|}{ Multivariate } \\
\hline & $O R(95 \% C l)$ & $P$-value & $\mathrm{aOR}(95 \% C l)$ & $P$-value \\
\hline Age (years)* & $1.05(1.01-1.09)$ & 0.007 & - & - \\
\hline Homeless & $3.34(1.64-6.78)$ & $<0.001$ & $2.64(1.23-5.68)$ & 0.013 \\
\hline Injection drug user & $9.42(3.27-27.09)$ & $<0.001$ & $5.37(1.81-15.93)$ & 0.002 \\
\hline Time using drugs (decades) & $1.25(1.09-1.43)$ & $<0.001$ & $1.22(1.05-1.42)$ & 0.008 \\
\hline Primary care assistance & $0.34(0.12-1.01)$ & 0.050 & $0.56(0.18-1.73)$ & 0.321 \\
\hline Opioid substitution therapy & $3.42(1.71-6.85)$ & $<0.001$ & $1.95(0.91-4.16)$ & 0.081 \\
\hline
\end{tabular}

Statistical analysis: The association analysis was performed using logistic regression. $\left(^{*}\right)$, age was discarded in multivariate analysis because it was highly correlated with time using drugs $(r=0.601 ; P<0.001)$

OR odds ratio; $a O R$ adjusted odds ratio; $95 \%$ Cl 95\% confidence interval

4.5-8.7\%)], which were confirmed by a serological HIV assay performed on DBS samples (100\% of concordance). All participants received their HIV test results at the POC, and they were offered the support of an educator/ navigator and specialized medical care at the hospital. Among the 35 individuals with positive HIV antibodies, 34 reported a previous diagnosis of HIV infection, and 27 (76\%) reported taking ART. Of the 35 HIV-positive patients, $28(80 \%)$ were retained in HIV medical care in 2018 and only $22(62.9 \%)$ in 2020 . No significant differences were found when the population was stratified by homeless, PWID, and decades of drug use $(P>0.05)$.

\section{Factors associated with a positive result in the HIV test}

HIV-infected patients were older, more often homeless, long-term drug users, injecting was the main drug administration route, and were on opioid substitution therapy, but they do not usually go to their primary care center (Table 1).

We also performed a multivariate logistic regression for these significant variables, finding that only three factors were independently related to HIV infection (Table 2): homelessness [adjusted odds ratio (aOR) 3.16; $P=0.003$ ], PWID (aOR 5.95; $P=0.001$ ), and decades of drug use $(\mathrm{aOR} 1.98 ; P=0.001)$. Among patients with a positive HIV antibody test, we also found a higher prevalence of homeless $(P<0.001$; Fig. $1 \mathrm{~A})$ and injection drug use (PWID) $(P<0.001$; Fig. 1B), and more decades of drug use $(P=0.002$; Fig. $1 C)$.

\section{HCV screening and linkage to care in HIV-infected people}

The prevalence of HCV antibodies was higher in HIVinfected subjects than in HIV uninfected participants (Fig. $2 \mathrm{~A} ; 51.4 \%$ vs $27.1 \% ; P=0.002$ ). Furthermore, the prevalence of active hepatitis C (HCV RNA test positive) was $34.3 \%$ in HIV patients and $22.3 \%$ in non-HIV participants (Fig. 2B; $P=0.103$ ). Of the $12 \mathrm{HIV}$-infected subjects with active HCV infection, 10 (83.3\%) were located and contacted to deliver the HCV test results (median delivery time of 19 days (interquartile range $=14-25$ )). Of these, 5 (41.7\%) had an appointment at the hospital, were seen by a physician, and subsequently started HCV therapy. Finally, only 4 (33.3\%) patients achieved SVR, $75 \%$ of those who began HCV therapy (Fig. 2C). Overall, we did not find significant differences in the linkage to care between HIV-uninfected and HIV-infected patients $(P>0.05)$.

\section{Discussion}

We performed a prospective observational study in PWUD from a shantytown in Madrid to estimate the HIV seroprevalence and the HCV/HIV coinfection proportion among PWUD. Furthermore, the effectiveness of referral to a specialized clinical care unit was also evaluated. This strategy involved using a mobile unit to search and reach potential participants, POC testing, and a navigator to refer and accompany the PWUD to the hospital. Our most relevant findings were the following: (i) HIV seroprevalence was $6.6 \%$, higher in homeless, PWID, and long-term drug users; and the vast majority of HIVinfected PWUD already knew their HIV infection, and $75 \%$ reported to be on ART; (ii) retention in care among HIV-infected PWUD was low during the study period (80\%) and two years after completing the HIV screening study (62.9\%); (iii) one-third of HIV-infected PWUD were coinfected with $\mathrm{HCV}$, and of these, only a third started treatment and were cured.

As is widely known, HIV transmission is high among PWID due to risky behaviors, such as unsafe injections. Homelessness in itself is also a risk factor for HIV infection [26]. This could be explained because independent risk factors, such as injection drug use, engaging in unsafe injection drug-use practices, mental health disorders, and a history of incarceration, are common in this population $[27,28]$. Our study is in accordance with previous estimates of HIV prevalence among PWUD 

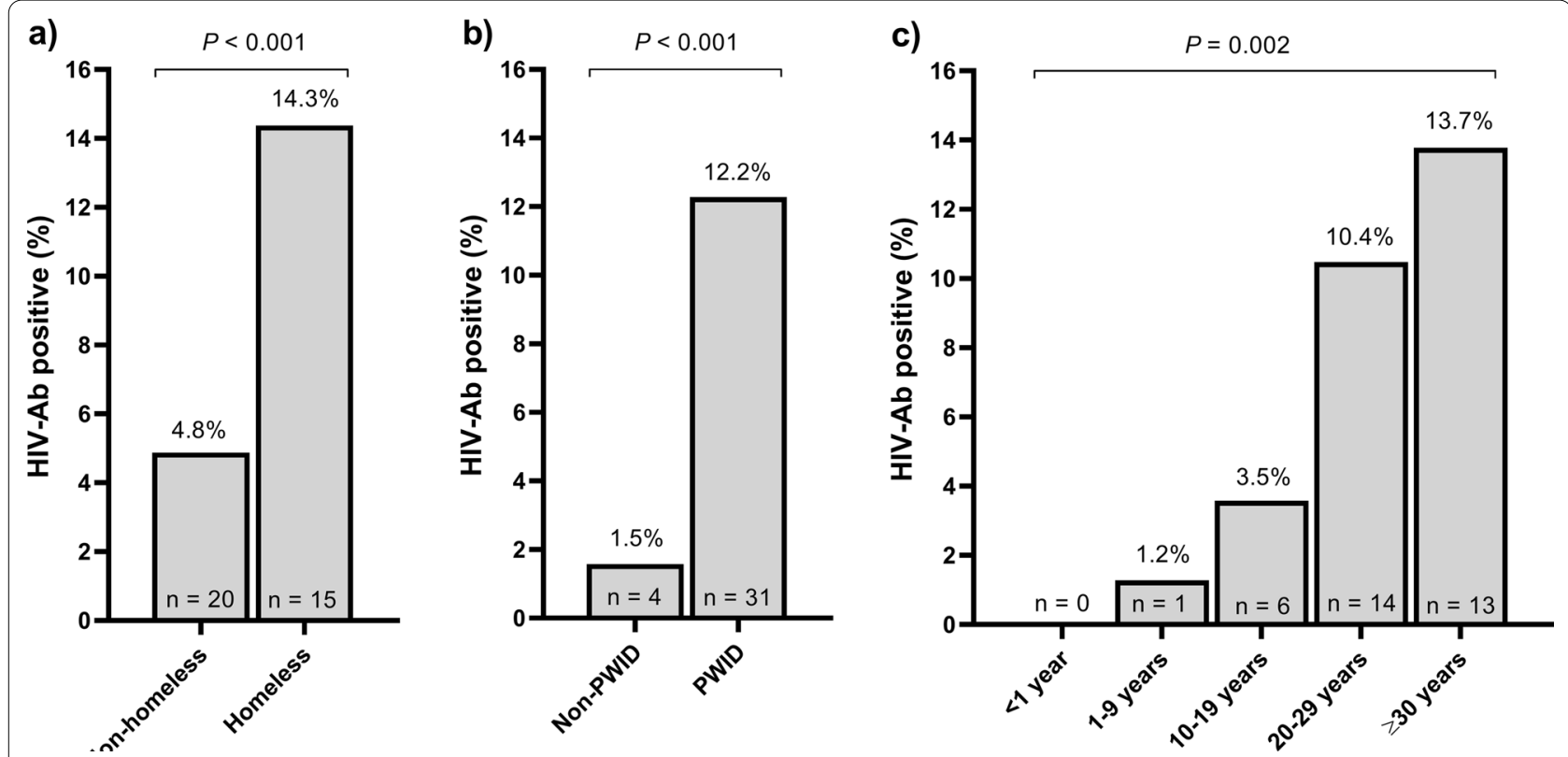

Fig. 1 Prevalence of HIV infection in people who use drugs (PWUD) from Cañada Real Galiana. a Population stratified by homeless; $\mathbf{b}$ population stratified by injection drug users; c population stratified by decades of drug use. PWID people who injected drugs; HIV human immunodeficiency virus; HIV-Ab antibodies against HIV; P-value, level of significance

in Western and Central Europe [29], and confirms the higher HIV prevalence in homeless PWUD screened and people with a longer drug injection duration. In the last years, growing evidence has shown the harmful effect of housing instability on the health and social outcomes of PWID, including an elevated risk of HIV and HCV acquisition [30]. Indeed, homeless PWID often faces profound disadvantage and have multiple competing needs [31]. Therefore, a comprehensive approach that provides housing and addresses many of the interlinked health and social concerns of this population is necessary to reduce HIV risk in this population.

Long-term retention in HIV care remains a challenge in vulnerable populations [32], and substance use is the most cited predictor of low retention [33]. However, other factors (e.g., medical comorbidities, addiction severity, and psychiatric disorders, among others) may interact and influence behaviors and health outcomes, such as adherence and retention of ART in care [34]. The previous step of retention in care is linkage to care, and our study was focused on the linkage to care, but there was also a follow-up period in which measures were implemented to promote retention in care. In our study, only two-thirds of the participants were retained in HIV medical care two years later, and although there is no gold standard for measuring retention in care, this value is as high as other published studies [35]. The role of navigators and the mobile units using HIV GenXpert to reinforce the linkage and retention to care in critical populations attended and screened at a POC (allowing retesting and retreatment) should be explored in further studies. In this way, expanding this focus to retention in HIV care (vs ART adherence alone) offers a more holistic point of view of HIV management and moves away from the purely medical model to account for psychosocial issues and physical comorbidities, specific to vulnerable populations, in conjunction with medication adherence. Moreover, no differences were found when the population was stratified by injection practices, homeless, and decades of drug use, possibly due to the low sample size. We think that a larger sample could demonstrate the previous findings.

We found a high prevalence of HIV/HCV coinfected patients with detectable HCV-RNA, although this group has had early access to direct-acting antiviral therapy [36], mainly because these patients were being followed in HIV clinics. While HIV specialists may continue to play a vital role in integrated and holistic care for all populations included marginalized populations [37, 38], hospital referrals are strictly necessary to start ART or hepatitis $C$ therapy in vulnerable people who are not retained in care.

The current study has several limitations. First, the study design was observational, the sample size was small, and it was conducted in a single city, which may reduce the generalizability of our findings. Second, 

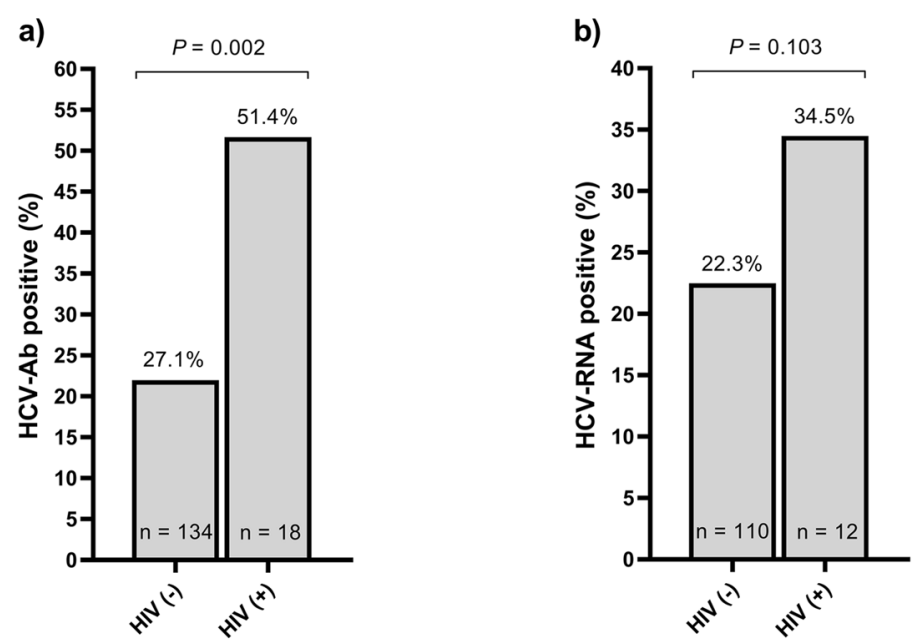

c)

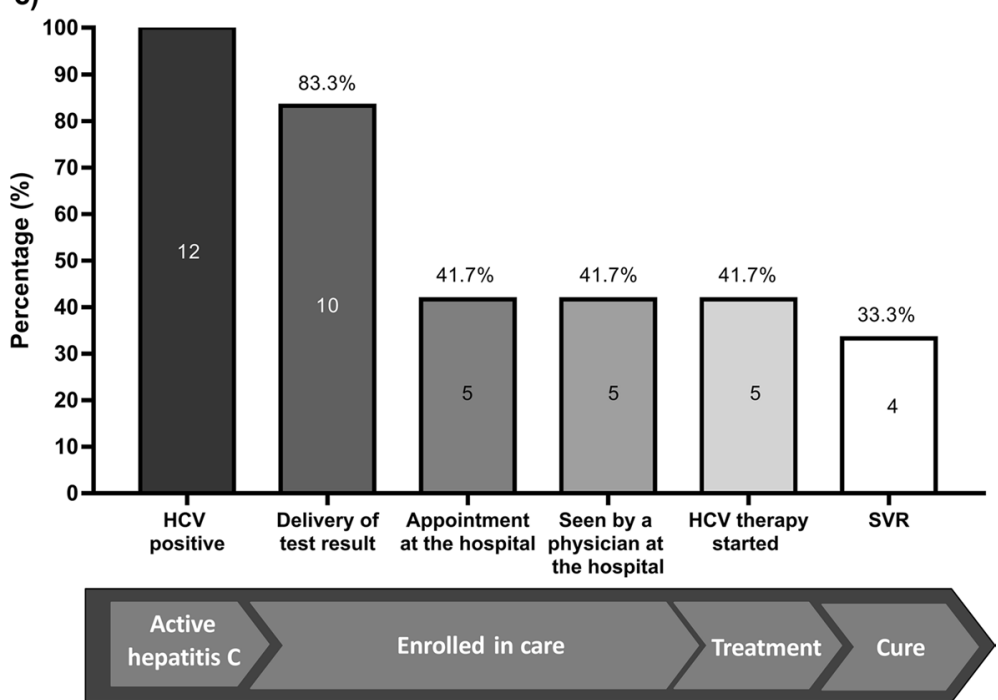

Fig. 2 Prevalence of hepatitis C infection (a) and linkage to care (b) among HIV-infected drug users in Cañada Real Galiana. HIV human immunodeficiency virus; HCV hepatitis C virus; HCV-Ab antibodies against HCV; HCV-RNA HCV ribonucleic acid; SVR sustained virological response; $P$-value level of significance

some data collected in the questionnaire may not be completely reliable; but this bias may be minimal because the data were collected by trained personnel. Third, some participants could have changed their residence, and therefore, no information was available on HIV linkage to care. Fourth, we assumed that patients were in retention in care by self-reports in the interview, but this information was not confirmed. Fifth, HIV viral load data were not available to corroborate if they were on effective ART and virologically suppressed. Sixth, no incentives or economic compensation were offered, so some participants may not have been included in the study. However, the educators provided food and drinks while the participants were waiting for their results. The refusal rate was no calculated.

\section{Conclusions}

We found almost no new HIV-infected PWUD, but their cascade of HIV care was low, particularly longterm HIV retention in care, and continues to be a challenge in this population at risk. The high frequency of active hepatitis $\mathrm{C}$ in HIV-infected PWUD reflects the need for $\mathrm{HCV}$ screening and reinforcing the link to care. 


\section{Abbreviations}

aOR: Adjusted odds ratio; ART: Antiretroviral therapy; DBS: Fingerstick dried blood spot; HCV: Hepatitis C virus; HIV: Human immunodeficiency virus; POC: Point of care; PWID: People who have injected drugs; PWUD: People who use drugs; SVR: Sustained virological response.

\section{Acknowledgements}

We acknowledge the patients' involvement in this study and the NGO "Madrid Positivo".

\section{Authors' contributions}

Funding body: SR and PR. Study concept and design: PR, JV and SR. Patient selection and clinical data acquisition: PR, JV, GC, JT, JTM, and NMR. Laboratory assays: MJMG, IC, and SV. Statistical analysis and interpretation of data: SR. Drafting the manuscript: PR, JV, and SR. Critical revision of the manuscript for relevant intellectual content: SVM. Supervision and visualization: PR and SR. All authors read and approved the final manuscript.

\section{Funding}

This work was funded by a research grant from Merck Sharpe \& Dohme (Grant Number MISP IIS\#54846) and Instituto de Salud Carlos III (ISCII; Grant Numbers PI20CIII/00004, and RD16CIII/0002/0002 to SR). The funders had no role in the study design, data collection, analysis, decision to publish, or preparation of the manuscript.

\section{Availability of data and materials}

Datasets used and analyzed during the current study may be available from the corresponding author upon reasonable request.

\section{Declarations}

\section{Ethics approval and consent to participate}

All participants signed their written informed consent. The study was carried out according to the Declaration of Helsinki. The study was approved by the Research Ethics Committee of ISCIII (CEI PI 77_2015-v2) and Hospital Gregorio Marañón (409/15).

\section{Consent for publication}

Not applicable.

\section{Competing interests}

The authors declare that they have no competing interests.

\section{Originality}

The authors confirm that the material contained herein is entirely original.

\section{Author details}

${ }^{1}$ Hospital Universitario Infanta Leonor, Madrid, Spain. ${ }^{2}$ Universidad Complutense de Madrid (UCM), Madrid, Spain. ${ }^{3}$ Instituto de Investigación Sanitaria Gregorio Marañón (liSGM), Madrid, Spain. ${ }^{4}$ Unidad de Reducción de Daños "SMASD", Madrid, Spain. ${ }^{5}$ Unidad de Infección Viral e Inmunidad, Centro Nacional de Microbiología, Instituto de Salud Carlos III, Carretera Majadahonda- Pozuelo, Km 2.2, 28220 Majadahonda, Madrid, Spain.

Received: 10 June 2021 Accepted: 8 August 2021

Published online: 19 August 2021

\section{References}

1. Rashti R, Sharafi H, Alavian SM, Moradi Y, Mohamadi Bolbanabad A, Moradi G. Systematic review and meta-analysis of global prevalence of HBsAg and HIV and HCV antibodies among people who inject drugs and female sex workers. Pathogens. 2020;9(6):432.

2. Degenhardt L, Peacock A, Colledge S, Leung J, Grebely J, Vickerman P, et al. Global prevalence of injecting drug use and sociodemographic characteristics and prevalence of HIV, HBV, and HCV in people who inject drugs: a multistage systematic review. Lancet Glob Health. 2017;5:e1192-207.
3. Abdul-Quader AS, Feelemyer J, Modi S, Stein ES, Briceno A, Semaan S, et al. Effectiveness of structural-level needle/syringe programs to reduce HCV and HIV infection among people who inject drugs: a systematic review. AIDS Behav. 2013;17:2878-92.

4. Catalani C, Philbrick W, Fraser H, Mechael P, Israelski DM. mHealth for HIV treatment \& prevention: a systematic review of the literature. Open AIDS J. 2013;7:17-41.

5. Platt L, Minozzi S, Reed J, Vickerman P, Hagan H, French C, et al. Needle syringe programmes and opioid substitution therapy for preventing hepatitis C transmission in people who inject drugs. Cochrane Database Syst Rev. 2017;9:CD012021.

6. Aspinall EJ, Nambiar D, Goldberg DJ, Hickman M, Weir A, Van Velzen E, et al. Are needle and syringe programmes associated with a reduction in HIV transmission among people who inject drugs: a systematic review and meta-analysis. Int J Epidemiol. 2014;43:235-48.

7. Larney S, Peacock A, Leung J, Colledge S, Hickman M, Vickerman P, et al. Global, regional, and country-level coverage of interventions to prevent and manage HIV and hepatitis C among people who inject drugs: a systematic review. Lancet Glob Health. 2017;5:e1208-20.

8. Strathdee SA, Hallett TB, Bobrova N, Rhodes T, Booth R, Abdool R, et al. HIV and risk environment for injecting drug users: the past, present, and future. Lancet. 2010;376:268-84.

9. Altice FL, Azbel L, Stone J, Brooks-Pollock E, Smyrnov P, Dvoriak S, et al The perfect storm: incarceration and the high-risk environment perpetuating transmission of HIV, hepatitis C virus, and tuberculosis in Eastern Europe and Central Asia. Lancet. 2016;388:1228-48.

10. Galea S, Vlahov D. Social determinants and the health of drug users: socioeconomic status, homelessness, and incarceration. Public Health Rep. 2002;117:S135-145.

11. Lucidarme D, Bruandet A, llef D, Harbonnier J, Jacob C, Decoster A, et al. Incidence and risk factors of HCV and HIV infections in a cohort of intravenous drug users in the North and East of France. Epidemiol Infect. 2004;132:699-708.

12. Samo RN, Altaf A, Agha A, Pasha O, Rozi S, Memon A, et al. High HIV incidence among persons who inject drugs in Pakistan: greater risk with needle sharing and injecting frequently among the homeless. PLoS One. 2013;8:e81715.

13. Kamarulzaman A, Altice FL. Challenges in managing HIV in people who use drugs. Curr Opin Infect Dis. 2015;28:10-6.

14. Yehia BR, Schranz AJ, Umscheid CA, Lo RV. The treatment cascade for chronic hepatitis $C$ virus infection in the United States: a systematic review and meta-analysis. PLoS ONE. 2014;9:e101554.

15. ECDC. Public health guidance on HIV, hepatitis B and C testing in the EU/ EEA - An integrated approach. In., SCIENTIFIC ADVICE edn. Stockholm, Sweden: European Centre for Disease Prevention and Control; 2018 $1-101$

16. Chevaliez S. Strategies for the improvement of HCV testing and diagnosis. Expert Rev Anti Infect Ther. 2019;17:341-7.

17. Eisinger RW, Fauci AS. Ending the HIV/AIDS Pandemic(1). Emerg Infect Dis. 2018;24:413-6.

18. Hogg RS. Understanding the HIV care continuum. Lancet HIV 2018;5:e269-70.

19. Drew RS, Rice B, Ruutel K, Delpech V, Attawell KA, Hales DK, et al. HIV continuum of care in Europe and Central Asia. HIV Med. 2017;18:490-9.

20. World Health Organization. Consolidated guidelines on the use of antiretroviral drugs for treating and preventing HIV infection: recommendations for a public health approach. 2nd ed. Geneva: World Health Organization; 2016

21. van Santen DK, Coutinho RA, van den Hoek A, van Brussel G, Buster $M$, Prins M. Lessons learned from the Amsterdam Cohort Studies among people who use drugs: a historical perspective. Harm Reduct J. 2021;18(1):2.

22. Ryan P, Valencia J, Cuevas G, Troya J, Ramon C, Rodriguez A, et al. HCV screening based on dried blood samples and linkage to care in people who use drugs: a prospective study. Int J Drug Policy. 2021;92:103134.

23. Tang W, Chen W, Amini A, Boeras D, Falconer J, Kelly H, et al. Diagnostic accuracy of tests to detect Hepatitis C antibody: a meta-analysis and review of the literature. BMC Infect Dis. 2017;17(Suppl 1):695.

24. Harris PA, Taylor R, Thielke R, Payne J, Gonzalez N, Conde JG. Research electronic data capture (REDCap)-a metadata-driven methodology and 
workflow process for providing translational research informatics support. J Biomed Inform. 2009;42:377-81.

25. Vazquez-Moron S, Ryan P, Ardizone-Jimenez B, Martin D, Troya J, Cuevas $\mathrm{G}$, et al. Evaluation of dried blood spot samples for screening of hepatitis $\mathrm{C}$ and human immunodeficiency virus in a real-world setting. Sci Rep. 2018;8:1858.

26. Vincent W, Lin J, Veloso D, Miller D, McFarland W. Homelessness, HIV testing, and the reach of public health efforts for people who inject drugs, San Francisco, California. Drug Alcohol Depend. 2021;221:108560.

27. Williams SP, Bryant KL. Sexually transmitted infection prevalence among homeless adults in the United States: a systematic literature review. Sex Transm Dis. 2018:45:494-504.

28. Fokuo JK, Masson CL, Anderson A, Powell J, Bush D, Ricco M, et al. Recommendations for implementing hepatitis $\mathrm{C}$ virus care in homeless shelters: the stakeholder perspective. Hepatol Commun. 2020;4:646-56.

29. UNAIDS. People who inject drugs. In: The gap report 2014. Geneva, Switzerland: Joint United Nations Programme on HIV/AIDS; 2014: 1-17.

30. Aldridge RW, Story A, Hwang SW, Nordentoft M, Luchenski SA, Hartwell $\mathrm{G}$, et al. Morbidity and mortality in homeless individuals, prisoners, sex workers, and individuals with substance use disorders in highincome countries: a systematic review and meta-analysis. Lancet. 2018;391:241-50.

31. Zivanovic R, Milloy MJ, Hayashi K, Dong H, Sutherland C, Kerr T, et al. Impact of unstable housing on all-cause mortality among persons who inject drugs. BMC Public Health. 2015;15:106.
32. Thida A, Tun ST, Zaw SK, Lover AA, Cavailler P, Chunn J, et al. Retention and risk factors for attrition in a large public health ART program in Myanmar: a retrospective cohort analysis. PLoS ONE. 2014;9:e108615.

33. Lourenco L, Colley G, Nosyk B, Shopin D, Montaner JS, Lima VD, Group SHAS. High levels of heterogeneity in the HIV cascade of care across different population subgroups in British Columbia, Canada. PLoS ONE. 2014;9:e115277.

34. Bulsara SM, Wainberg ML, Newton-John TRO. Predictors of adult retention in HIV care: a systematic review. AIDS Behav. 2018:22:752-64.

35. Hartzler B, Dombrowski JC, Williams JR, Crane HM, Eron JJ, Geng EH, et al. Influence of substance use disorders on 2-year hiv care retention in the United States. AIDS Behav. 2018:22:742-51.

36. d'Arminio Monforte A, Cozzi-Lepri A, Ceccherini-Silberstein F, De Luca A, Lo Caputo S, Castagna A, et al. Access and response to direct antiviral agents (DAA) in HIV-HCV co-infected patients in Italy: data from the Icona cohort. PLOS ONE. 2017;12:e0177402.

37. Giordano TP, Hartman C, Gifford AL, Backus LI, Morgan RO. Predictors of retention in HIV care among a national cohort of US veterans. HIV Clin Trials. 2009; 10:299-305.

38. Dombrowski JC, Simoni JM, Katz DA, Golden MR. Barriers to HIV care and treatment among participants in a public health HIV care relinkage program. AIDS Pat Care STDs. 2015;29:279-87.
Ready to submit your research? Choose BMC and benefit from:

- fast, convenient online submission

- thorough peer review by experienced researchers in your field

- rapid publication on acceptance

- support for research data, including large and complex data types

- gold Open Access which fosters wider collaboration and increased citations

- maximum visibility for your research: over 100M website views per year

At BMC, research is always in progress.

Learn more biomedcentral.com/submissions 